\title{
Targeting the PD-1 Axis with Pembrolizumab for Recurrent or Metastatic Cancer of the Uterine Cervix: A Brief Update
}

\author{
Yannick Verhoeven ${ }^{1}\left(\mathbb{D}\right.$, Delphine Quatannens ${ }^{1}\left(\mathbb{D}\right.$, , Xuan Bich Trinh ${ }^{1,2}$, An Wouters ${ }^{1}{ }^{(}$, Evelien L.J. Smits ${ }^{1,3} \mathbb{D}$, \\ Filip Lardon ${ }^{1} \mathbb{D}$, Jorrit De Waele ${ }^{1,+} \mathbb{D}$ and Peter A. van Dam ${ }^{1,2,4, *,+}$ \\ 1 Center for Oncological Research (CORE), Integrated Personalized \& Precision Oncology Network (IPPON), \\ University of Antwerp, Universiteitsplein 1, B-2610 Wilrijk, Belgium; \\ Yannick.Verhoeven@uantwerpen.be (Y.V.); Delphine.Quatannens@uantwerpen.be (D.Q.); \\ XuanBich.Trinh@uza.be (X.B.T.); An.Wouters@uantwerpen.be (A.W.); Evelien.Smits@uza.be (E.L.J.S.); \\ Filip.Lardon@uantwerpen.be (F.L.); Jorrit.DeWaele@uantwerpen.be (J.D.W.) \\ 2 Multidisciplinary Oncologic Centre Antwerp (MOCA), Antwerp University Hospital, Drie Eikenstraat 655, \\ B-2650 Edegem, Belgium \\ 3 Center for Cell Therapy and Regenerative Medicine, Antwerp University Hospital, Drie Eikenstraat 655, \\ B-2650 Edegem, Belgium \\ 4 Gynaecologic Oncology Unit, Antwerp University Hospital, Drie Eikenstraat 655, B-2650 Edegem, Belgium \\ * Correspondence: peter.vandam@uza.be; Tel.: +32-3821-4105; Fax: +32-3218-8750 \\ + Shared senior authorship.
}

check for

updates

Citation: Verhoeven, Y.; Quatannens,

D.; Trinh, X.B.; Wouters, A.; Smits,

E.L.J.; Lardon, F.; De Waele, J.; van

Dam, P.A. Targeting the PD-1 Axis with Pembrolizumab for Recurrent or Metastatic Cancer of the Uterine Cervix: A Brief Update. Int. J. Mol. Sci. 2021, 22, 1807. https://doi.org/ $10.3390 /$ ijms 22041807

Academic Editor: Claudiu T. Supuran

Received: 31 December 2020

Accepted: 9 February 2021

Published: 11 February 2021

Publisher's Note: MDPI stays neutral with regard to jurisdictional claims in published maps and institutional affiliations.

Copyright: (c) 2021 by the authors. Licensee MDPI, Basel, Switzerland. This article is an open access article distributed under the terms and conditions of the Creative Commons Attribution (CC BY) license (https:/ / creativecommons.org/licenses/by/ $4.0 /)$.

\begin{abstract}
Even though cervical cancer is partly preventable, it still poses a great public health problem throughout the world. Current therapies have vastly improved the clinical outcomes of cervical cancer patients, but progress in new systemic treatment modalities has been slow in the last years. Especially for patients with advanced disease this is discouraging, as their prognosis remains very poor. The pathogen-induced nature, the considerable mutational load, the involvement of genes regulating the immune response, and the high grade of immune infiltration, suggest that immunotherapy might be a promising strategy to treat cervical cancer. In this literature review, we focus on the use of PD-1 blocking therapy in cervical cancer, pembrolizumab in particular, as it is the only approved immunotherapy for this disease. We discuss why it has great clinical potential, how it opens doors for personalized treatment in cervical cancer, and which trials are aiming to expand its clinical use.
\end{abstract}

Keywords: metastatic; recurrent; cervical cancer; PD-1; PD-L1; biomarker; pembrolizumab; immunotherapy; clinical trial

\section{Introduction}

To date, cervical cancer (CC) is one of the most preventable malignancies. Populationwide cytological screening and vaccination campaigns against human papilloma virus (HPV) have led to a 75\% reduction in mortality of CC over the past 50 years in industrialized countries $[1,2]$. Future perspectives are promising too. Australia, for example, is projected to reduce its CC cases to fewer than four per 100,000 women by 2035, combining a nationwide HPV vaccination and cytologic screening program, putting them on track to be the first country in the world to eliminate CC as a public health problem [3]. Nevertheless, we must remain cautious not to rely too much on the protective features of these measures. The latest reports show that CC accounts for an estimated 570,000 new cases and 311,000 deaths annually [4]. Thus, despite prevention efforts, CC still ranks as the fourth most prevalent cancer and a leading cause of cancer-related deaths in women worldwide [4]. Moreover, Van Kriekinge et al. estimated that if in $2014 \mathrm{HPV}$ vaccine rates of $70 \%$ would have been achieved globally, CC incidence would have decreased, with about 345,000 new cases and mortality with about 178,000 deaths [5]. Even though such a scenario sounds very promising, CC mortality rates would still exceed those of multiple other malignancies in 
women, like head-and-neck cancer, leukemia, lymphoma, melanoma, and cancer of the brain and central nervous system [6]. Today, we are far from achieving the $70 \%$ threshold in industrialized countries, let alone throughout the world. Considering the growing vaccine hesitancy in a considerable part of the population, this margin is not expected to be acquired soon either. Therefore, effective treatments for CC remain highly warranted.

A small proportion of $\mathrm{CCs}(<5 \%)$ are truly HPV-negative after sensitive HPV assessment. These tumors are more frequently of the non-squamous subtype, diagnosed at advanced stages, show higher prevalence of lymph node metastases, and have an impaired prognosis $[7,8]$. HPV-negative CCs have distinct molecular characteristics that show similarities with endometrial cancer, while having a significantly higher epithelialmesenchymal transition mRNA score and a lower frequency of the APOBEC mutagenesis signature compared to their HPV-positive counterparts $[9,10]$. This implies that these tumors should be considered as a distinct subtype, which is more difficult to screen for (being HPV-negative), cannot be prevented by HPV vaccination and may need a different treatment approach that more resembles the management of endometrial cancer.

Current first-line management of CC consists of surgery, (chemo)radiotherapy for locally advanced disease, and platinum-based chemotherapy with or without the antiVEGF drug, bevacizumab, for metastatic CC [11,12]. These treatments have reduced the mortality rate of $\mathrm{CC}$, but their effectiveness is now reaching a plateau. Especially for patients with advanced stage $\mathrm{CC}$, this is unfortunate, because their prognosis remains very poor, with a median overall survival (OS) of about 17 months and an estimated 5 -year survival of about $17 \%$ [13]. In addition, current treatment strategies are generally associated with unwanted adverse events (AEs) and a reduced quality of life for the patient. In recent decades, little progress has been made in the development of better systemic treatments, and early clinical trials with targeted therapies have yet to identify drugs with superior response rates [14]. Therefore, there is an unmet need for innovative therapies to increase durable responses, reduce substantial toxicities associated with current treatment strategies, and improve patients' lives and outcomes. One such strategy to battle the cancer and improve the long-term benefits of treatment is to stimulate the patient's own immune system to eradicate residual cancer cells and prevent recurrence by inducing antitumor immunity via immunotherapy. In the present review of the literature, we discuss the use of programmed cell death protein 1 (PD-1 or CD279) -targeting immunotherapy for the treatment of recurrent or metastatic CC. We zoom in on the clinical context of pembrolizumab, as this compound is implemented in the second line for the treatment of recurrent or metastatic CC.

\section{Rationale for PD-1 Blocking Therapy in Cervical Cancer}

A sustained HPV infection has a crucial etiological role in most CC [15]. Recently, some of the regulatory networks involved in the carcinogenesis of this disease have been identified, including TGF-beta, C-MYC, MAPK signaling, and APOBEC mutagenesis $[9,10]$. In a landmark study on invasive CC that was conducted as part of The Cancer Genome Atlas (TCGA) project, amplifications in multiple checkpoint-controlling immune targets have been identified in the tumor cells, such as programmed death ligand 1 (PD-L1, encoded by the CD274 gene) and 2 (PD-L2, encoded by PDCD1LG2), and in the long non-coding RNA of BRCA4 in the immune cells that regulates the expression of cytosolic immune effector genes, perforin and granzyme A [9]. In addition, CC has been shown to rank amongst the top ten tumors with most somatic mutations, which is associated with a high frequency of neoantigen formation and a better response to immunotherapy $[16,17]$. CC also ranks among the top ten tumors with the richest tumor immune infiltrate, with $\mathrm{CD}^{+}$cytotoxic $\mathrm{T}$ lymphocytes (CTLs) and macrophages $(\mathrm{M} \Phi)$ being the most enriched infiltrates, creating a hostile immune environment for the tumor [18,19]. Together, the pathogen-induced nature of the disease (HPV antigens), the considerable mutational load, the strong involvement of genes regulating the immune response, and the relatively high grade of immune infiltration suggests that immunotherapeutic strategies may be promising 
to treat CC $[20,21]$. This hypothesis is supported by multiple studies that confirm that clinical responses are seen in CC treated with immune checkpoint blockade (ICB), alone or in combination with other therapies [22].

In recent years, the targeted inhibition of the PD-1 axis for the treatment of cancer has garnered a lot of attention. PD-1 is a co-inhibitory cell-surface receptor, expressed mainly in B- and T-cells, that acts to restrain T-cell-mediated immune responses when activated by its ligands, PD-L1 or PD-L2 [23]. As such, the PD-1 pathway functions as a built-in protection mechanism that tampers the adaptive immune response, thereby preventing immune cell overstimulation and maintaining self-tolerance. Hence, it has an essential role in regulating the balance within the immune system. During persistent antigen encounter, however - like in cancer - PD-1 expression and that of its ligands is often high and sustained and can therefore limit protective immunity in favor of the disease [24]. As a result, CTLs encounter dysfunction and exhaustion within the tumor microenvironment (TME), which leads to adaptive immune resistance. CTLs have long been proven essential in the battle against cancer, so losing these soldiers to cancer-induced immunosuppression could be an important reason why the disease can thrive. Thus, countering this process with PD1-inhibiting compounds could be a valid strategy to treat cancer. Early clinical trials showed promising results with durable anti-tumor immune responses [25], which led to the approval of multiple PD-1- and PD-L1-targeting monoclonal antibodies for therapeutic use in various cancer types (Table 1 ).

Table 1. Current FDA/EMA approved PD-1 axis blockers.

\begin{tabular}{|c|c|c|c|c|c|}
\hline Target & $\begin{array}{c}\text { Active } \\
\text { Substance }\end{array}$ & Trade Name & $\begin{array}{l}\text { Marketing } \\
\text { Holder }\end{array}$ & FDA Approval & EMA Approval \\
\hline \multirow[t]{3}{*}{$P D-1$} & Nivolumab & OPDIVO $^{\circledR}$ & $\begin{array}{l}\text { Bristol-Myers } \\
\text { Squibb Pharma } \\
\text { EEIG }\end{array}$ & $\begin{array}{c}\text { Since 2014: } \\
\text { cHL, ESCC, HCC, HNSCC, } \\
\text { Melanoma, MSI-H/dMMR CRC, } \\
\text { NSCLC, RCC, SCLC, Urothelial } \\
\text { Carcinoma }\end{array}$ & $\begin{array}{c}\text { Since 2015: } \\
\text { cHL, HNSCC, } \\
\text { Melanoma, NSCLC, } \\
\text { RCC, Urothelial } \\
\text { Carcinoma }\end{array}$ \\
\hline & Pembrolizumab & KEYTRUDA $^{\circledR}$ & $\begin{array}{l}\text { Merck Sharp \& } \\
\text { Dohme B.V. }\end{array}$ & $\begin{array}{c}\text { Since 2014: } \\
\text { CC, cHL, cSCC, ESCC, Endometrial } \\
\text { Carcinoma, Gastric or Esophageal } \\
\text { Junction Cancer, HCC, HNSCC, } \\
\text { Melanoma, MCC, MSI-H/dMMR } \\
\text { Cancer, NSCLC, PMBCL, RCC, SCLC, } \\
\text { TMB-H Cancer, TNBC, Urothelial } \\
\text { Carcinoma }\end{array}$ & $\begin{array}{c}\text { Since 2015: } \\
\text { cHL, HNSCC, } \\
\text { Melanoma, NSCLC, } \\
\text { RCC, Urothelial } \\
\text { Carcinoma }\end{array}$ \\
\hline & Cemiplimab & LIBTAYO $^{\circledR}$ & $\begin{array}{l}\text { Regeneron } \\
\text { Ireland U.C. }\end{array}$ & $\begin{array}{l}\text { Since 2018: } \\
\text { cSCC }\end{array}$ & $\begin{array}{l}\text { Since 2019: } \\
\text { cSCC }\end{array}$ \\
\hline \multirow[t]{3}{*}{$P D-L 1$} & Atezolizumab & TECENTRIQ $^{\circledR}$ & $\begin{array}{l}\text { Roche } \\
\text { Registration } \\
\text { GmbH }\end{array}$ & $\begin{array}{l}\text { Since 2016: } \\
\text { HCC, Melanoma, NSCLC, SCLC, } \\
\text { TNBC, Urothelial Carcinoma }\end{array}$ & $\begin{array}{c}\text { Since 2017: } \\
\text { HCC, NSCLC, SCLC, } \\
\text { TNBC, Urothelial } \\
\text { Carcinoma }\end{array}$ \\
\hline & Avelumab & BAVENCIO $^{\circledR}$ & $\begin{array}{l}\text { Merck Europe } \\
\text { B.V. }\end{array}$ & $\begin{array}{c}\text { Since 2017: } \\
\text { MCC, RCC, Urothelial Carcinoma }\end{array}$ & $\begin{array}{c}\text { Since 2018: } \\
\text { MCC, RCC, } \\
\text { Urothelial Carcinoma }\end{array}$ \\
\hline & Durvalumab & IMFINZI $^{\circledR}$ & AstraZeneca AB & $\begin{array}{c}\text { Since 2017: } \\
\text { NSCLC, SCLC, Urothelial Carcinoma }\end{array}$ & $\begin{array}{l}\text { Since 2019: } \\
\text { NSCLC }\end{array}$ \\
\hline
\end{tabular}

$\mathrm{CC}=$ Cervical Cancer; $\mathrm{cHL}$ = classical Hodgkin Lymphoma; CRC = Colorectal Cancer; cSCC = cutaneous Squamous Cell Carcinoma; $\mathrm{dMMR}=$ deficient MisMatch Repair; EMA = European Medicines Agency; ESCC = Esophageal Squamous Cell Carcinoma; FDA = U.S. Food and Drug Administration; HCC = Hepatocellular Carcinoma; HNSCC = Head and Neck Squamous Cell Carcinoma; MCC = Merkel Cell Carcinoma; MSI-H = MicroSatellite Instability-High; (N)SCLC = (Non-)Small Cell Lung Carcinoma; PMBCL = Primary Mediastinal Large B-Cell Lymphoma; RCC = Renal Cell Carcinoma; TMB-H = Tumor Mutational Burden-High; TNBC = Triple-Negative Breast Cancer; PD-(L)1 = Programmed Death-(Ligand)1. 
In CC, members of the PD-1 axis are upregulated during cancer progression [26]. PDL1 expression is more apparent in squamous cell carcinoma (34\%) than in adenocarcinoma $(17 \%)$ and adenosquamous carcinoma (29\%) [27-30]. The genes encoding PD-L1 and PD-L2, the CD274 gene and PDCD1LG2, respectively, were co-amplified or gained extra chromosomes in $67 \%$ of CC cases [31]. Several studies found that HPV-positivity is correlated with increased PD-L1 expression [32-34]. In the TCGA cohort, PD-L1 methylation was negatively correlated with PD-L1 mRNA expression and associated with HPV infection [35]. This suggests that PD-L1 methylation is a mechanism involved in transcriptional silencing after HPV infection in CC, as also described for other proteins [36]. Moreover, a higher level of PD-1/PD-L1 expression was shown in tumor-infiltrating lymphocytes (TILs) in CC, compared to other tumor types [34]. PD-L1 engagement on T-cells was recently shown to promote the self-tolerance and suppression of neighboring macrophages and effector T-cells in cancer and could predict response to anti-PD-L1 therapy [37,38]. On this basis, together with the immunogenicity of CC, several studies investigated the role of PD-1 blocking therapy in CC. The promising results following the use of the PD-1 blocking antibody, pembrolizumab, in recurrent or metastatic CC, in the KEYNOTE-28 (NCT02054806) and KEYNOTE-158 (NCT02628067) trials, led the Food and Drug Administration (FDA), on 12 June 2018, to approve pembrolizumab for the second-line treatment of PD-L1-positive metastatic or recurrent CC. The European Medicines Agency (EMA), on the other hand, has not yet approved pembrolizumab for the treatment of CC, even in PD-L1-positive tumors.

KEYNOTE-28 (NCT02054806) was a nonrandomized phase IB basket trial of 20 different cohorts in 477 patients with PD-L1-positive advanced solid tumors-including 24 CC cases-that received $10 \mathrm{mg} / \mathrm{kg}$ pembrolizumab monotherapy every two weeks for up to 24 months [39]. PD-L1-positivity was assessed using an archived FFPE tumor sample or a newly obtained core or excisional biopsy sample and defined as membranous staining on $\geq 1 \%$ in a modified proportion score or interface pattern as assessed using a laboratorydeveloped prototype IHC assay with the $22 \mathrm{C} 3$ antibody (combined positive score [CPS]). At a median follow-up of 11 months, overall response rate was $17 \%$ (95\% CI, $5 \%$ to $37 \%$ ). Four patients (17\%) achieved a confirmed partial response (PR), and three patients (13\%) had stable disease. The six-month progression free survival (PFS) was $13 \%$ and six-month OS was $66.7 \%$. The median duration of response for the four patients who achieved a PR was 5.4 months ( 4.1 to 7.5 months). Treatment-related AEs were experienced by 18 patients $(75 \%)$ : rash $(n=2 ; 21 \%)$ and pyrexia $(n=4 ; 17 \%)$ were observed and occurred in $\geq 10 \%$ of patients. Five patients experienced grade 3 treatment-related AEs. No grade 4 AEs or deaths were observed. Two patients discontinued treatment because of grade 3 treatment-related AEs (Guillain-Barré syndrome and colitis). Immune-mediated AEs were observed in six patients and included rash $(n=2$; grade 3$)$, colitis $(n=1$; grade 3$)$, GuillainBarré syndrome ( $n=1$; grade 3$)$, hyperthyroidism $(n=1$; grade 2$)$, and hypothyroidism $(n=1$; grade 2$)$. These results suggest that, in patients with PD-L1-positive advanced CC, pembrolizumab demonstrates anti-tumor activity and exhibits a safety profile consistent with that seen in other tumor types.

KEYNOTE-158 (NCT02628067) is an ongoing phase II basket trial including 1595 patients with advanced solid tumors, of which the results of 98 patients with previously treated advanced CC have already been published [40]. A total of $82(83.7 \%)$ CC patients had PD-L1-positive tumors (as determined with CPS), of which 77 received one or more lines of chemotherapy. Pembrolizumab $200 \mathrm{mg} / \mathrm{kg}$ monotherapy was given every 3 weeks for two years until progression. The primary endpoint was objective response rate on RESIST, assessed by an independent radiological review, and median follow-up was 10.2 months. Objective responses were seen in 12 patients (12.2\%), all with a PD-L1-positive tumor (response rate in this group 12/82 =14.6\%), and in 11 out of the 77 patients previously treated with one or more lines of chemotherapy. At the time of interim analysis, the median duration of response was not reached (range $>3.7$ to 18.6 months). Median PFS was 2.1 months both in the entire population as in the PD-L1 group, and median OS was 9.4 and 11 months, respectively. Treatment-related AEs occurred in 64 (65.3\%) patients. The most 
common were hypothyroidism $(10.2 \%)$, loss of appetite $(9.2 \%)$, and fatigue $(9.2 \%)$. Grade 3 and 4 toxicity were seen in $12(12.2 \%)$ patients (most frequent elevated transaminases $3.1 \%$ ), which resulted in four patients $(4.1 \%)$ discontinuing treatment. Immune-related AEs were reported in $25.5 \%$ of patients, of which $5.1 \%$ were grade 3 or 4 (hepatitis $n=2$, skin reaction $n=2$, adrenal insufficiency $n=1$ ). The most commonly observed were hyperthyroidism $(11.2 \%)$ and hypothyroidism (9.2\%). No treatment-related deaths occurred. The authors concluded that pembrolizumab monotherapy demonstrated durable anti-tumor activity and manageable safety in patients with advanced CC. Based on these results, the FDA approved the use of pembrolizumab in patients with PD-L1-positive (CPS $\geq 1$ ) advanced CC, progressing during or after chemotherapy.

Different immunotherapy strategies for CC have been extensively investigated and were found to be safe and well-tolerated in early clinical trials [21]. For pembrolizumab, there are no formal contraindications in the clinic and grade 3-4 AEs are uncommon [41]. Most common side effects, including diarrhea, fever, nausea, pain, fatigue, rash, etc., can easily be managed with symptomatic treatments or by dose reduction. On rare occasions, more severe AEs occur, like endocrinopathies, hematological toxicity, severe skin reactions, and immune-related AEs (hepatitis, pneumonitis, nephritis, colitis, etc.). In such cases, pembrolizumab should be temporarily withheld and can be resumed when recovered to grade 1, according to the schemes provided by the manufacturer. Pembrolizumab should be permanently discontinued after any life-threatening adverse reaction and recurrent grade 2 or grade 3-4 immune-related AEs. During pregnancy, the PD-1/PD-L1 pathway was shown to maintain immune tolerance to the fetal allograft; therefore, fetal harm may occur when pembrolizumab is administered to a pregnant woman; however, currently, no human data are available on the risk of embryo-fetal toxicity [42].

Current treatment strategies have reduced the mortality rates of $\mathrm{CC}$ but are now reaching a plateau, leading to a stagnation of the treatment progress over the last years. These treatments do not specifically target cancer cells, and are therefore generally associated with unwanted AEs and a reduced quality of life for the patient. Hence, there is an unmet need for innovative therapies to increase durable responses, reduce substantial toxicities associated with current treatment strategies and improve patients' lives and outcomes. One such strategy that holds promise in all these features is immunotherapy, which has revolutionized the field of oncology in recent years. Benefits include its potential to specifically target cancer cells, to induce systemic anti-tumor immune memory and to mediate long-term survival. Even though the response rates observed in the KEYNOTE-28 and KEYNOTE-158 trials are limited, these features underline the advantages of (anti-PD-1) immunotherapy over the current standard of care for CC.

\section{Biomarkers for PD-1 Blocking Therapy in Cervical Cancer}

The response rates to ICB across different tumor types emphasize the importance of biomarkers to identify the patients that will benefit, allowing for personalized treatment. PD-L1 protein expression can be used to evaluate the efficacy of immunotherapy, as it is an indicator for immune cell activation via the interferon gamma cascade [43]. Several studies have shown that PD-1 and PD-L1 expression are mainly regulated by interferon gamma signaling via the IL-6/JAK/STAT pathway [44-51]. More importantly, PD-L1 expression can be used as a biomarker to predict the effect of immunotherapy. Scoring for PD-L1 expression is usually performed via immunohistochemistry (IHC) on formalin-fixed paraffin-embedded (FFPE) tissues. For this, two main PD-L1 scoring strategies are used, the CPS and the tumor proportion score (TPS). The CPS is evaluated by IHC with the antiPD-L1 mouse monoclonal antibody, 22C3 (pharmDx, Agilent DAKO), and is determined by the number of PD-L1 staining cells (tumor cells, lymphocytes, macrophages), divided by the total number of viable tumor cells, multiplied by 100. The TPS is also based on IHC with the 22C3 antibody and is defined as the percentage of viable tumor cells with partial or complete PD-L1 membrane staining at any intensity. Both the CPS and TPS scoring systems are used in the clinic to decide if a patient is suitable for PD-1 targeting therapy [52]. 
In the KEYNOTE-158 trial, response of CC patients to pembrolizumab was significantly correlated to both the CPS ( $p=0.008)$ and TPS $(p=0.023)$, but the CPS identified more responders [40]. Therefore, the CPS is now a validated quantitative scoring system for the detection of PD-L1 on CC FFPE tissues, which determines the eligibility of a CC patient for pembrolizumab treatment, according to the FDA. Based upon the KEYNOTE-28 and KEYNOTE-158 trials, a CPS $\geq 1$ is required before pembrolizumab treatment is justified. Intra- and interobserver concordance of this assay is above $98 \%$ in CC [53]. IHC for PD-L1 with $22 \mathrm{C} 3$ is a companion assay that is now used in many studies beyond CC to identify patients who may benefit from pembrolizumab [52].

The prognostic role of the expression of members of the PD- 1 axis in CC is not very clear and highly context-specific, depending on different factors like the source, transience, and pattern of expression. For example, PD-1 is also expressed on the immunosuppressive regulatory T-cells (Tregs). Thus, PD-L1 expression can support anti-tumor immunity by attenuating the immunosuppressive effects of Tregs. As such, CC patients with a relative excess of infiltrating Tregs show a better survival when the tumor was PD-L1-positive [54]. PD-1 expression on CTLs, on the other hand, is detrimental in CC and might be important to predict the efficacy of PD-1-blocking therapy [55]. Another important prognostic factor is the heterogeneity of the expression, which is difficult to detect. Significantly poorer survival rates were seen in CC patients with diffuse PD-L1 expression compared to patients with marginal PD-L1 expression on the tumor-stroma interface [26]. Another, barely detectable factor is the transience of PD-L1 expression due to fluctuating interferon gamma expression in the TME, which might explain the varying response rates of PD-1 targeting therapy in CC [56]. Real-time screening methods like immuno-Positron Emission Tomography (immune-PET) with radiolabeled antibodies, might better predict response to targeted (immuno)therapies [57]. This technique combines the superior sensitivity of PET imaging with the benefits of the high targeting specificity of monoclonal antibodies. As such, it can provide information on whole-body biomarker distribution or (heterogenic) tumor target expression and act as a companion diagnostic tool in vivo in a non-invasive and longitudinal manner. Currently, multiple immuno-PET imaging techniques are under investigation for PD-L1 biomarker assessment (NCT03746704, NCT04006522, NCT03514719, NCT03065764) [58-60].

Recent evidence suggests that a large mutational burden will generate neoantigens for T-cell recognition, leading to the recruitment of CTLs that are mandatory for effective immunotherapy [61]. While a high tumor mutational burden (TMB) has been shown to predict the response to ICB and clinical benefit in some studies [62-67], it failed to do so in several others [68-71]. Ott et al. analyzed PD-L1 expression, the T-cell inflamed gene expression profile (GEP), and non-synonymous tumor mutations assessed by whole exome sequencing (TMB) in patients enrolled in the KEYNOTE-28 trial. PD-L1 expression, a T-cell inflamed GEP, and a high TMB each predicted response to pembrolizumab in multiple tumor types. The correlations between TMB and GEP or PD-L1 were low. However, response patterns indicate that patients with tumors with high levels of both TMB and one of the inflammatory markers (GEP or PD-L1) have the highest probability of responding. Yang et al. developed an immune-related gene (IRG) signature to predict survival and response to immunotherapy in CC patients [72]. They used the TCGA RNA sequencing data to estimate proportions of 22 types of infiltrating immune cells with the CIBERSORT algorithm and downloaded mutation data of 304 CC patients from the TCGA data portal to calculate the TMB. A prognostic IRG signature based on 11 genes was constructed and this proved to be an independent prognostic factor for OS and PFS in CC patients. Seven of those genes were identified as high-risk signatures (LEPR, PRL, NRP1, TNFRSF10B, TNFRSF10A, PLAU, ANGPTL5) and four were protective (PRLHR, NR2F2, IFI30, IGF1). Based on these signatures, a risk score was established, and the patients were divided into high- and low-risk groups according to the median cutoff of the risk score. In the high-risk group, CTLs and resting mast cells, which were found to be associated with better OS in this study, were lower; and activated mast cells, associated with poorer OS, were higher, 
compared with the low-risk group. The 11-IRG signature low-risk group represented a more immunogenic phenotype that was more inclined to respond to ICB treatment. In the same study however, the authors could not detect significant differences in TMB and PD-L1 expression between the 11-IRG signature high-risk group and the low-risk group.

Tumor-infiltrating immune subsets might also predict the efficacy of PD-1 targeting therapy. For instance, using triple-color immunofluorescence confocal microscopy, de Vos van Steenwijk et al. could show that a dense infiltration of intraepithelial matured M1-M $\phi$ and a high CTL/Treg ratio are independent prognostic factors in patients with CC [73]. More recently, the same group identified a $\mathrm{CD} 8{ }^{+} \mathrm{FoxP} 3{ }^{+} \mathrm{CD} 25^{+} \mathrm{T}$-cell subset as a potential therapeutic target for PD-1-blocking therapy, implicating that this subset may also serve as a predictive biomarker for PD-1-blocking therapy [55].

Ngoi et al. performed a small study specifically focusing on the TME and the molecular genetic profile of tumor samples of four patients with metastatic CC, treated with off-label second line pembrolizumab [74]. All patients received $2 \mathrm{mg} / \mathrm{kg}$ pembrolizumab in a 3weekly regimen upon progression. One patient had a long-lasting PR and remained stable for at least 21 months at the time of reporting the series. The other patients had progressive disease. The responder had a CPS for PD-L1 of 1, and somatic mutations in ERBB4, PIK3CA and $R B 1$ were detected.

\section{Clinical Trials Investigating Pembrolizumab in Patients with Cervical Cancer}

Currently there are 28 active recruiting and non-recruiting clinical trials assessing the role of pembrolizumab (combination) therapy in patients with CC. Eleven of those evaluate its therapeutic potential solely in CC patients (Table 2) and are discussed below. In addition, 17 clinical studies investigate the role of pembrolizumab monotherapy, or in combination with chemotherapy, radiotherapy, targeted therapy, immunotherapy, and/or gene therapy in multiple cancer types, including CC (Table 3).

Table 2. Current recruiting and non-recruiting clinical trials assessing pembrolizumab solely in patients with cervical cancer.

\begin{tabular}{|c|c|c|c|c|c|c|c|}
\hline NCT & Acronym & Phase & Intervention & Enrollment & Status & Completion & Ref. \\
\hline \multicolumn{8}{|c|}{ Chemotherapy combinations } \\
\hline NCT04238988 & MITO CERV 3 & II & $\begin{array}{l}\text { Neoadjuvant Carbo + } \\
\text { Paclitaxel + Pembro }\end{array}$ & 45 & Not yet recruiting & September 2023 & \\
\hline \multicolumn{8}{|c|}{ Targeted therapy combinations } \\
\hline NCT04230954 & \multirow{4}{*}{$\begin{array}{c}\text { InnovaTV } \\
\text { 205/ENGOT-cx8 }\end{array}$} & II & Cabozantinib + Pembro & 39 & Recruiting & January 2022 & \multirow{4}{*}{ [75] } \\
\hline NCT03786081 & & I-II & $\begin{array}{c}\text { Tisotumab Vedotin + } \\
\text { Pembro }\end{array}$ & 175 & $\begin{array}{l}\text { Active, not } \\
\text { recruiting }\end{array}$ & April 2022 & \\
\hline NCT04641728 & & II & Olaparib + Pembro & 28 & Not yet recruiting & December 2023 & \\
\hline NCT04483544 & & II & Olaparib + Pembro & 48 & Recruiting & November 2031 & \\
\hline \multicolumn{8}{|c|}{ Immunotherapy combinations } \\
\hline NCT03444376 & & I-II & GX-188E + Pembro & 60 & Recruiting & December 2023 & [76] \\
\hline NCT03108495 & & II & LN-145 + Pembro & 138 & Recruiting & December 2026 & {$[77]$} \\
\hline \multicolumn{8}{|c|}{ Multiple combinations } \\
\hline NCT03144466 & PAPAYA & I & Cis + RT + BT + Pembro & 1 & Terminated & January 2019 & \\
\hline NCT02635360 & & II & Cis + BT + Pembro & 88 & Recruiting & October 2021 & [78] \\
\hline NCT03635567 & KEYNOTE-826 & III & $\begin{array}{c}\text { Cis + Carbo + Paclitaxel + } \\
\text { Bevacizumab + Pembro or } \\
\text { Placebo }\end{array}$ & 600 & $\begin{array}{l}\text { Active, not } \\
\text { recruiting }\end{array}$ & November 2022 & [79] \\
\hline NCT04221945 & $\begin{array}{c}\text { ENGOT- } \\
\text { cx11/KEYNOTE- } \\
\text { A18 }\end{array}$ & III & $\begin{array}{c}\text { Cis }+ \text { EBRT }+ \text { BT }+ \text { Pembro } \\
\quad \text { or Placebo }\end{array}$ & 980 & Recruiting & December 2024 & [80] \\
\hline NCT03367871 & & II & $\begin{array}{c}\text { Cis + Carbo + Paclitaxel + } \\
\text { Bevacizumab + Pembro }\end{array}$ & 40 & Recruiting & October 2025 & \\
\hline
\end{tabular}

BT = Brachytherapy; Carbo = Carboplatin; Cis = Cisplatin; ERBT = External Beam Radiotherapy; Pembro = Pembrolizumab; $\mathrm{RT}=$ Radiotherapy . 
Table 3. Current clinical trials assessing pembrolizumab in multiple malignancies, among which cervical cancer.

\begin{tabular}{|c|c|c|c|c|c|c|c|}
\hline NCT & Acronym & Phase & Intervention & Enrollment & Status & Completion & Ref. \\
\hline \multicolumn{8}{|c|}{ Monotherapy } \\
\hline NCT02054806 & KEYNOTE-28 & I & Pembro & 477 & $\begin{array}{l}\text { Active, not } \\
\text { recruiting }\end{array}$ & December 2023 & [39] \\
\hline NCT02628067 & KEYNOTE-158 & II & Pembro & 1595 & Recruiting & June 2026 & [40] \\
\hline NCT03755739 & & II-III & Pembro & 200 & Recruiting & November 2033 & \\
\hline \multicolumn{8}{|c|}{ Targeted therapy combinations } \\
\hline NCT04432857 & & I & AN0025 + Pembro & 84 & Recruiting & March 2023 & \\
\hline NCT04357873 & PEVOsq & II & Vorinostat + Pembro & 111 & Recruiting & December 2024 & \\
\hline NCT03849469 & DUET-4 & I & $\mathrm{XmAb}^{\circledR} 22841+$ Pembro & 242 & Recruiting & March 2027 & \\
\hline \multicolumn{8}{|c|}{ Immunotherapy combinations } \\
\hline NCT04099277 & & I & LY3435151 + Pembro & 2 & Terminated & March 2020 & \\
\hline NCT03277352 & & I-II & $\begin{array}{c}\text { INCAGN01876 + Epacadostat + } \\
\text { Pembro }\end{array}$ & 10 & Completed & July 2020 & \\
\hline NCT03228667 & QUILT-3.055 & II & $\begin{array}{c}\mathrm{N}-803+\underset{\text { Pembro }+/- \text { PD-L1 }}{\text { t-haNK }} \\
\text { Pal }\end{array}$ & 636 & Recruiting & August 2021 & \\
\hline NCT04234113 & & I & SO-C101 + Pembro & 96 & Recruiting & March 2022 & \\
\hline NCT03841110 & & I & FT500 + Pembro + /- IL-2 & 76 & Recruiting & June 2022 & \\
\hline NCT03799003 & & I & ASP1951 + Pembro & 435 & Recruiting & October 2023 & \\
\hline NCT03454451 & & I & CPI-006 + Pembro & 378 & Recruiting & December 2023 & [81] \\
\hline NCT03311334 & & I-II & DSP-7888 + Pembro & 104 & Recruiting & February 2024 & \\
\hline \multicolumn{8}{|c|}{ Gene therapy combinations } \\
\hline NCT03544723 & & II & $\begin{array}{c}\text { Ad-p53 + ICI, among which } \\
\text { Pembro }\end{array}$ & 40 & Recruiting & December 2022 & \\
\hline \multicolumn{8}{|c|}{ Multiple combinations } \\
\hline NCT03192059 & PRIMMO & II & $\begin{array}{c}\text { RT + Vit D + Aspirin + } \\
\text { Lansoprazole }+ \\
\text { Cyclophosphamide + Curcumin }+ \\
\text { Pembro }\end{array}$ & 43 & Recruiting & June 2022 & \\
\hline NCT04116320 & AM-003 & I & $\begin{array}{c}\text { Echopulse + Imiquimod + } \\
\text { Pembro }\end{array}$ & 32 & Recruiting & May 2023 & \\
\hline NCT04652076 & GYNET & I-II & NP137+ Cis + Carbo + Pembro & 240 & Not yet recruiting & November 2024 & \\
\hline
\end{tabular}

Carbo = Carboplatin; Cis = Cisplatin; ICI = Immune Checkpoint Inhibitor; Pembro = Pembrolizumab; RT = Radiotherapy.

\subsection{Pembrolizumab Combined with Chemotherapy}

The MITO CERV3 trial (NCT04238988) is currently the only trial investigating pembrolizumab combined with chemotherapy solely in patients with CC. It is a single-arm multicenter phase II clinical trial evaluating the role of pembrolizumab in combination with carboplatin-paclitaxel chemotherapy in 45 patients with locally advanced CC. Patients with stage IB2-IIB CC (according to the International Federation of Gynaecology and Obstetrics [FIGO] stage system) will be treated with three cycles of neoadjuvant carboplatin (AUC 5 D1, q21)-paclitaxel (175 mg/mq D1, q21) chemotherapy in combination with pembrolizumab (200 mg flat dose every 3 weeks). After three cycles, non-progressing patients will undergo radical surgery. After surgery, patients presenting with high-risk factors (positive lymph nodes, positive parametria, positive surgical margins or at least two of the following risk factors between tumor diameter $>3 \mathrm{~cm}$, lymphovascular space invasion, stromal infiltration $>1 / 3$ ) will receive three cycles of adjuvant carboplatin-paclitaxel with pembrolizumab and maintenance with pembrolizumab $200 \mathrm{mg}$ every 3 weeks until progression, unacceptable toxicity, or patient consent withdrawal for up to 35 cycles.

\subsection{Pembrolizumab Combined with Targeted Therapy}

Currently, the NCT04230954, InnovaTV 205/ENGOT-cx8 (NCT03786081), NCT04641728, and NCT04483544 trials are investigating pembrolizumab in combination with targeted therapy solely in patients with CC. NCT04230954 is a single-arm, open label phase II trial to evaluate the efficacy and safety of cabozantinib (XL184; a small molecule inhibitor of the tyrosine kinases c-Met and VEGFR2, which also inhibits AXL and RET) plus pembrolizumab in 39 patients with recurrent, persistent and/or metastatic CC with PD-L1 tumor positivity. InnovaTV 205/ENGOT-cx8 (NCT03786081) is a seven-arm phase I-II clinical trial investi- 
gating the role of tisotumab vedotin (a drug conjugated monoclonal antibody-targeting tissue factor) monotherapy, and in combination with bevacizumab, pembrolizumab, or carboplatin, in 175 subjects with recurrent or stage IVB cervical cancer [75]. The phase I portion of the study is a dose escalation part, whereas the phase II portion is a dose expansion part. Both the NCT04641728 and NCT04483544 trials are single-arm phase II clinical studies aiming to investigate the use of combining pembrolizumab with the PARP inhibitor, Olaparib, in 28 and 48 patients, respectively, with recurrent or metastatic CC.

\subsection{Pembrolizumab Combined with Immunotherapy}

NCT03444376 and NCT03108495 are both investigating pembrolizumab in combination with other immunotherapy, solely in patients with CC. NCT03444376 is an ongoing single-arm, open-label phase IB-II clinical trial of the combination of GX-188E (a DNA vaccine shown to induce HPV E6- and E7-specific T-cell responses and lesion regression in patients with cervical precancer) with pembrolizumab in 60 patients with advanced, non-resectable HPV-positive CC. Most recently, their interim analysis of 36 patients, of which 26 patients were evaluable for interim activity assessment with at least one postbaseline tumor assessment at week 10, were published in The Lancet Oncology [76]. At 24 weeks, 11 (42\%; 95\% CI 23-63) of 26 patients achieved an overall response; four (15\%) had a complete response and seven (27\%) had a PR. A total of $16(44 \%)$ of 36 patients had treatment-related AEs of any grade and four $(11 \%)$ had grade 3-4 treatment-related AEs. Grade-3-increased aspartate aminotransferase, syncope, pericardial effusion, and hyperkalemia, and grade-4-increased alanine aminotransferase were reported in one patient each. No treatment-related deaths were reported. These results suggest that combinatorial treatment of GX-188E with pembrolizumab for patients with recurrent or metastatic CC is safe and showed preliminary anti-tumor activity, which could represent a new potential treatment option for this patient population. NCT03108495 is a five-arm, openlabel phase II interventional study evaluating the combination of pembrolizumab and adoptive cell therapy with autologous TIL infusion (LN-145), followed by IL-2, after a non-myeloablative lymphodepletion preparative regimen for the treatment of patients with recurrent, metastatic, or persistent CC [77].

\subsection{Pembrolizumab Combined with Multiple Other Therapies}

NCT02635360, KEYNOTE-826 (NCT03635567), ENGOT-cx11/KEYNOTE-A18 (NCT04221945), and NCT03367871 all investigate pembrolizumab in combination with multiple other therapies, solely in patients with CC. NCT02635360 is an ongoing phase II clinical study to evaluate the safety and effectiveness of pembrolizumab in combination with cisplatin chemotherapy and brachytherapy radiation (chemoradiation) for the treatment of advanced CC [78]. After chemoradiation is complete, 88 subjects will receive pembrolizumab $200 \mathrm{mg}$ IV every 21 days for 3 months during and after the chemoradiotherapy. The KEYNOTE-826 trial is a currently enrolling phase III double-blind randomized multicenter study evaluating the efficacy and tolerability of platinum- and taxane-based chemotherapy with or without pembrolizumab and/or bevacizumab for first-line treatment in patients with persistent, metastatic or recurrent CC [79]. A total of 600 eligible patients will be randomized 1:1 to chemotherapy (paclitaxel $175 \mathrm{mg} / \mathrm{m}^{2}+$ cisplatin 50 $\mathrm{mg} / \mathrm{m}^{2}$ or carboplatin AUC5 with or without bevacizumab $15 \mathrm{mg} / \mathrm{kg}$ ) + pembrolizumab $200 \mathrm{mg}$, or placebo every 3 weeks. Patients will be stratified according to metastasis status at diagnosis, planned bevacizumab use (yes or no) and tumor PD-L1 status (CPS $<1.1$ to $<10$, or $\geq 10$ ). Treatment will continue for maximum 35 cycles (about two years), until disease progression, unacceptable toxicity, or voluntary patient withdrawal. The ENGOT-cx11/KEYNOTE-A18 trial is a randomized phase III study of chemotherapy and radiotherapy with pembrolizumab or placebo to pembrolizumab for the treatment of locally advanced CC, aiming to enroll 980 patients [80]. Participants receive placebo or $200 \mathrm{mg}$ of pembrolizumab on Day 1 of each 3-week cycle (Q3W) for five cycles followed by placebo on Day 1 of each 6-week cycle (Q6W) for an additional 15 cycles. During the 
Q3W dosing period of placebo, participants receive concurrent chemoradiotherapy. The standard of care chemoradiotherapy regimen includes cisplatin $40 \mathrm{mg} / \mathrm{m} 2 \mathrm{IV}$ once per week (QW) for 5 weeks plus 45-50 Gray units (Gy) of external beam radiotherapy given over 40 days, followed by 25-30 Gy of brachytherapy given with the total duration of radiation treatment, not exceeding 56 days. $\mathrm{NCT03367871}$ is a phase II single arm study to evaluate the efficacy of the combination of standard chemotherapy with bevacizumab with Pembrolizumab in women with recurrent, persistent, or metastatic cervical cancer. On day 1 of each 21-day cycle, participants will be administered pembrolizumab $200 \mathrm{mg}$ (IV); chemotherapy including paclitaxel $175 \mathrm{mg} / \mathrm{m}^{2}$ or $135 \mathrm{mg} / \mathrm{m}^{2}$ (IV), and cisplatin 50 $\mathrm{mg} / \mathrm{m}^{2}$ (IV) or carboplatin AUC 5; and bevacizumab $15 \mathrm{mg} / \mathrm{kg}$ (IV).

\section{Concluding Remarks}

Limited clinical data exist on the use of PD-1-blocking therapy for CC, mainly provided by the KEYNOTE-28, KEYNOTE-158, and NCT03444376 trials. These trials suggest that PD-1 targeting therapy in CC has an acceptable toxicity profile, with fewer AEs than standard treatment, and some promising anti-tumor activity, especially in patients with PD-L1-positive tumors. On this behalf, the FDA, but not the EMA, approved the use of pembrolizumab for the treatment of recurrent or metastatic $\mathrm{CC}$ if the tumor shows a CPS of $\geq 1$. Even though CC is immunogenic, only low response rates are seen when the patients are treated with current ICB, including pembrolizumab [20]. Whereas belief in ICB for the treatment of CC is supported, consensus dictates that it currently does not live up to its full potential. Anti-CTLA-4 therapy with ipilimumab could not produce equivalent response rates in $\mathrm{CC}$, as seen with pembrolizumab [82]. The activity of such ICB agents in monotherapy appears to be limited in CC; however, their combinations can elicit synergistic effects [83]. Ongoing efforts are being made to discover biomarkers to stratify for the patients that will benefit from this approach and to identify and target other pathways that might tamper the effect of current ICB therapy [51,84-86]. Some interesting parameters still lack current clinical data of pembrolizumab in CC, such as duration of the effects, long-term AEs, and correlation with other predictive biomarker approaches. The latter is an important factor. The FDA approving pembrolizumab based on a predictive biomarker is the first step in personalized treatment for CC, which should pose an example to implement more personalized and precision approaches for CC treatment. Real-time target assessment with immuno-PET imaging using radiolabeled monoclonal antibodies should be considered for this matter.

Standard treatments have had an immense effect on CC patients' lives and outcome but are now falling short of benefitting the subgroup of patients in the most need of effective treatment. PD-1 targeting immunotherapy poses a potential solution for these patients, but still lacks sufficient effect to be implemented in the first line. Nevertheless, this approach poses a solid basis for further strategies in CC, around which future investigations should work.

Author Contributions: Y.V. designed the paper. Drafting and revision of the manuscript was performed by all authors. All authors have read and agreed to the published version of the manuscript.

Funding: Y.V. received funding from the Emmanuel van der Schueren research grant (grant number CS 16628) of Kom op tegen Kanker (Stand up to Cancer), the Flemish cancer society. Y.V. is also a research fellow of the Research Foundation Flanders (FWO; fellowship number 1S69721N).

Institutional Review Board Statement: Not applicable.

Informed Consent Statement: Not applicable.

Acknowledgments: The authors would like to thank the editor and reviewers of this manuscript for their time, efforts and valuable suggestions.

Conflicts of Interest: P.A.v.D. has received a grant from Amgen to perform an academic trial on denosumab in cervical cancer. The sponsorship has no link with this manuscript. The other authors declare no conflicts of interest. 


\section{References}

1. Canfell, K. Towards the global elimination of cervical cancer. Papillomavirus Res. 2019, 8, 100170. [CrossRef]

2. Quinn, M.; Babb, P.; Jones, J.; Allen, E. Effect of screening on incidence of and mortality from cancer of cervix in England: Evaluation based on routinely collected statistics. BMJ (Clin. Res. Ed.) 1999, 318, 904-908. [CrossRef]

3. Hall, M.T.; Simms, K.T.; Lew, J.B.; Smith, M.A.; Brotherton, J.M.; Saville, M.; Frazer, I.H.; Canfell, K. The projected timeframe until cervical cancer elimination in Australia: A modelling study. Lancet Public Health 2019, 4, e19-e27. [CrossRef]

4. Arbyn, M.; Weiderpass, E.; Bruni, L.; de Sanjosé, S.; Saraiya, M.; Ferlay, J.; Bray, F. Estimates of incidence and mortality of cervical cancer in 2018: A worldwide analysis. Lancet Glob. Health 2020, 8, e191-e203. [CrossRef]

5. Van Kriekinge, G.; Castellsagué, X.; Cibula, D.; Demarteau, N. Estimation of the potential overall impact of human papillomavirus vaccination on cervical cancer cases and deaths. Vaccine 2014, 32, 733-739. [CrossRef] [PubMed]

6. World Health Organization International Agency for Research on Cancer (IARC). GLOBOCAN 2020: Estimated Cancer Incidence, Mortality and Prevalence Worldwide in 2020. Available online: http:/ / globocan.iarc.fr/Pages/fact_sheets_cancer.aspx (accessed on 1 November 2020).

7. Nicolás, I.; Marimon, L.; Barnadas, E.; Saco, A.; Rodríguez-Carunchio, L.; Fusté, P.; Martí, C.; Rodriguez-Trujillo, A.; Torne, A.; Del Pino, M.; et al. HPV-negative tumors of the uterine cervix. Mod. Pathol. 2019, 32, 1189-1196. [CrossRef]

8. Rodríguez-Carunchio, L.; Soveral, I.; Steenbergen, R.D.; Torné, A.; Martinez, S.; Fusté, P.; Pahisa, J.; Marimon, L.; Ordi, J.; del Pino, M. HPV-negative carcinoma of the uterine cervix: A distinct type of cervical cancer with poor prognosis. Bjog Int. J. Obstet. Gynaecol. 2015, 122, 119-127. [CrossRef] [PubMed]

9. Integrated genomic and molecular characterization of cervical cancer. Nature 2017, 543, 378-384. [CrossRef]

10. van Dam, P.A.; van Dam, P.J.; Rolfo, C.; Giallombardo, M.; van Berckelaer, C.; Trinh, X.B.; Altintas, S.; Huizing, M.; Papadimitriou, K.; Tjalma, W.A.; et al. In silico pathway analysis in cervical carcinoma reveals potential new targets for treatment. Oncotarget 2016, 7, 2780-2795. [CrossRef]

11. Marth, C.; Landoni, F.; Mahner, S.; McCormack, M.; Gonzalez-Martin, A.; Colombo, N. Cervical cancer: ESMO Clinical Practice Guidelines for diagnosis, treatment and follow-up. Ann. Oncol. 2017, 28, iv72-iv83. [CrossRef]

12. Tewari, K.S.; Sill, M.W.; Long, H.J., 3rd; Penson, R.T.; Huang, H.; Ramondetta, L.M.; Landrum, L.M.; Oaknin, A.; Reid, T.J.; Leitao, M.M.; et al. Improved survival with bevacizumab in advanced cervical cancer. N. Engl. J. Med. 2014, 370, 734-743. [CrossRef] [PubMed]

13. National Cancer Institute: Cancer Stat Facts: Cervix Uteri Cancer. Available online: https://seer.cancer.gov/statfacts/html/ cervix.html (accessed on 1 November 2020).

14. van Dam, P.A.; Rolfo, C.; Ruiz, R. Neoadjuvant trials can accelerate research on novel systemic treatment modalities in cancer of the uterine cervix. Eur. J. Surg. Oncol. 2017, 43, 2245-2247.

15. zur Hausen, H. Papillomaviruses in the causation of human cancers-A brief historical account. Virology 2009, 384, 260-265. [CrossRef]

16. Alexandrov, L.B.; Nik-Zainal, S.; Wedge, D.C.; Aparicio, S.A.; Behjati, S.; Biankin, A.V.; Bignell, G.R.; Bolli, N.; Borg, A.; Børresen-Dale, A.L.; et al. Signatures of mutational processes in human cancer. Nature 2013, 500, 415-421. [CrossRef] [PubMed]

17. Samstein, R.M.; Lee, C.H.; Shoushtari, A.N.; Hellmann, M.D.; Shen, R.; Janjigian, Y.Y.; Barron, D.A.; Zehir, A.; Jordan, E.J.; Omuro, A.; et al. Tumor mutational load predicts survival after immunotherapy across multiple cancer types. Nat. Genet. 2019, 51, 202-206. [CrossRef]

18. Mandal, R.; Şenbabaoğlu, Y.; Desrichard, A.; Havel, J.J.; Dalin, M.G.; Riaz, N.; Lee, K.W.; Ganly, I.; Hakimi, A.A.; Chan, T.A.; et al. The head and neck cancer immune landscape and its immunotherapeutic implications. JCI Insight 2016, 1, e89829. [CrossRef]

19. Wang, J.; Li, Z.; Gao, A.; Wen, Q.; Sun, Y. The prognostic landscape of tumor-infiltrating immune cells in cervical cancer. Biomed. Pharmacother. Biomed. Pharmacother. 2019, 120, 109444. [PubMed]

20. De Felice, F.; Marchetti, C.; Palaia, I.; Ostuni, R.; Muzii, L.; Tombolini, V.; Benedetti Panici, P. Immune check-point in cervical cancer. Crit. Rev. Oncol./Hematol. 2018, 129, 40-43. [CrossRef]

21. Kagabu, M.; Nagasawa, T.; Fukagawa, D.; Tomabechi, H.; Sato, S.; Shoji, T.; Baba, T. Immunotherapy for Uterine Cervical Cancer. Healthcare 2019, 7, 108. [CrossRef]

22. Dyer, B.A.; Zamarin, D.; Eskandar, R.N.; Mayadev, J.M. Role of Immunotherapy in the Management of Locally Advanced and Recurrent/Metastatic Cervical Cancer. J. Natl. Compr. Cancer Netw. JNCCN 2019, 17, 91-97. [CrossRef]

23. Riley, R.S.; June, C.H.; Langer, R.; Mitchell, M.J. Delivery technologies for cancer immunotherapy. Nat. Rev. Drug Discov. 2019, 1. [CrossRef]

24. Pauken, K.E.; Wherry, E.J. Overcoming T cell exhaustion in infection and cancer. Trends Immunol. 2015, 36, 265-276. [CrossRef] [PubMed]

25. Salmaninejad, A.; Valilou, S.F.; Shabgah, A.G.; Aslani, S.; Alimardani, M.; Pasdar, A.; Sahebkar, A. PD-1/PD-L1 pathway: Basic biology and role in cancer immunotherapy. J. Cell. Physiol. 2019, 234, 16824-16837. [CrossRef] [PubMed]

26. Heeren, A.M.; Punt, S.; Bleeker, M.C.; Gaarenstroom, K.N.; van der Velden, J.; Kenter, G.G.; de Gruijl, T.D.; Jordanova, E.S. Prognostic effect of different PD-L1 expression patterns in squamous cell carcinoma and adenocarcinoma of the cervix. Mod. Pathol. 2016, 29, 753-763. [CrossRef] 
27. Meng, Y.; Liang, H.; Hu, J.; Liu, S.; Hao, X.; Wong, M.S.K.; Li, X.; Hu, L. PD-L1 Expression Correlates With Tumor Infiltrating Lymphocytes And Response To Neoadjuvant Chemotherapy In Cervical Cancer. J. Cancer 2018, 9, 2938-2945. [CrossRef] [PubMed]

28. Feng, M.; Xu, L.; He, Y.; Sun, L.; Zhang, Y.; Wang, W. Clinical significance of PD-L1 (CD274) enhanced expression in cervical squamous cell carcinoma. Int. J. Clin. Exp. Pathol. 2018, 11, 5370-5378.

29. Reddy, O.L.; Shintaku, P.I.; Moatamed, N.A. Programmed death-ligand 1 (PD-L1) is expressed in a significant number of the uterine cervical carcinomas. Diagn. Pathol. 2017, 12, 45. [CrossRef]

30. Enwere, E.K.; Kornaga, E.N.; Dean, M.; Koulis, T.A.; Phan, T.; Kalantarian, M.; Köbel, M.; Ghatage, P.; Magliocco, A.M.; LeesMiller, S.P.; et al. Expression of PD-L1 and presence of CD8-positive T cells in pre-treatment specimens of locally advanced cervical cancer. Mod. Pathol. 2017, 30, 577-586. [CrossRef] [PubMed]

31. Howitt, B.E.; Sun, H.H.; Roemer, M.G.; Kelley, A.; Chapuy, B.; Aviki, E.; Pak, C.; Connelly, C.; Gjini, E.; Shi, Y.; et al. Genetic Basis for PD-L1 Expression in Squamous Cell Carcinomas of the Cervix and Vulva. JAMA Oncol. 2016, 2, 518-522.

32. Yang, W.; Song, Y.; Lu, Y.L.; Sun, J.Z.; Wang, H.W. Increased expression of programmed death (PD)-1 and its ligand PD-L1 correlates with impaired cell-mediated immunity in high-risk human papillomavirus-related cervical intraepithelial neoplasia. Immunology 2013, 139, 513-522. [CrossRef]

33. Liu, C.; Lu, J.; Tian, H.; Du, W.; Zhao, L.; Feng, J.; Yuan, D.; Li, Z. Increased expression of PD-L1 by the human papillomavirus 16 E7 oncoprotein inhibits anticancer immunity. Mol. Med. Rep. 2017, 15, 1063-1070. [CrossRef]

34. Mezache, L.; Paniccia, B.; Nyinawabera, A.; Nuovo, G.J. Enhanced expression of PD L1 in cervical intraepithelial neoplasia and cervical cancers. Mod. Pathol. 2015, 28, 1594-1602. [CrossRef]

35. Franzen, A.; Vogt, T.J.; Müller, T.; Dietrich, J.; Schröck, A.; Golletz, C.; Brossart, P.; Bootz, F.; Landsberg, J.; Kristiansen, G.; et al. PD-L1 (CD274) and PD-L2 (PDCD1LG2) promoter methylation is associated with HPV infection and transcriptional repression in head and neck squamous cell carcinomas. Oncotarget 2018, 9, 641-650. [CrossRef]

36. Tilborghs, S.; Corthouts, J.; Verhoeven, Y.; Arias, D.; Rolfo, C.; Trinh, X.B.; van Dam, P.A. The role of Nuclear Factor-kappa B signaling in human cervical cancer. Crit. Rev. Oncol./Hematol. 2017, 120, 141-150. [CrossRef]

37. Diskin, B.; Adam, S.; Cassini, M.F.; Sanchez, G.; Liria, M.; Aykut, B.; Buttar, C.; Li, E.; Sundberg, B.; Salas, R.D.; et al. PD-L1 engagement on $\mathrm{T}$ cells promotes self-tolerance and suppression of neighboring macrophages and effector $\mathrm{T}$ cells in cancer. Nat. Immunol. 2020, 21, 442-454. [CrossRef] [PubMed]

38. Herbst, R.S.; Soria, J.C.; Kowanetz, M.; Fine, G.D.; Hamid, O.; Gordon, M.S.; Sosman, J.A.; McDermott, D.F.; Powderly, J.D.; Gettinger, S.N.; et al. Predictive correlates of response to the anti-PD-L1 antibody MPDL3280A in cancer patients. Nature 2014, 515, 563-567. [CrossRef] [PubMed]

39. Ott, P.A.; Bang, Y.J.; Piha-Paul, S.A.; Razak, A.R.A.; Bennouna, J.; Soria, J.C.; Rugo, H.S.; Cohen, R.B.; O’Neil, B.H.; Mehnert, J.M.; et al. T-Cell-Inflamed Gene-Expression Profile, Programmed Death Ligand 1 Expression, and Tumor Mutational Burden Predict Efficacy in Patients Treated With Pembrolizumab Across 20 Cancers: KEYNOTE-028. J. Clin. Oncol. 2019, 37, $318-327$.

40. Chung, H.C.; Ros, W.; Delord, J.P.; Perets, R.; Italiano, A.; Shapira-Frommer, R.; Manzuk, L.; Piha-Paul, S.A.; Xu, L.; Zeigenfuss, S.; et al. Efficacy and Safety of Pembrolizumab in Previously Treated Advanced Cervical Cancer: Results From the Phase II KEYNOTE-158 Study. J. Clin. Oncol. 2019, 37, 1470-1478. [CrossRef] [PubMed]

41. Baxi, S.; Yang, A.; Gennarelli, R.L.; Khan, N.; Wang, Z.; Boyce, L.; Korenstein, D. Immune-related adverse events for anti-PD-1 and anti-PD-L1 drugs: Systematic review and meta-analysis. BMJ (Clin. Res. Ed.) 2018, 360, k793. [CrossRef]

42. Poulet, F.M.; Wolf, J.J.; Herzyk, D.J.; DeGeorge, J.J. An Evaluation of the Impact of PD-1 Pathway Blockade on Reproductive Safety of Therapeutic PD-1 Inhibitors. Birth Defects Res. Part BDev. Reprod. Toxicol. 2016, 107, 108-119. [CrossRef]

43. Garcia-Diaz, A.; Shin, D.S.; Moreno, B.H.; Saco, J.; Escuin-Ordinas, H.; Rodriguez, G.A.; Zaretsky, J.M.; Sun, L.; Hugo, W.; Wang, X.; et al. Interferon Receptor Signaling Pathways Regulating PD-L1 and PD-L2 Expression. Cell Rep. 2019, 29, 3766. [CrossRef] [PubMed]

44. Atsaves, V.; Tsesmetzis, N.; Chioureas, D.; Kis, L.; Leventaki, V.; Drakos, E.; Panaretakis, T.; Grander, D.; Medeiros, L.J.; Young, K.H.; et al. PD-L1 is commonly expressed and transcriptionally regulated by STAT3 and MYC in ALK-negative anaplastic large-cell lymphoma. Leukemia 2017, 31, 1633-1637. [CrossRef] [PubMed]

45. Austin, J.W.; Lu, P.; Majumder, P.; Ahmed, R.; Boss, J.M. STAT3, STAT4, NFATc1, and CTCF regulate PD-1 through multiple novel regulatory regions in murine T cells. J. Immunol. 2014, 192, 4876-4886. [CrossRef] [PubMed]

46. Bu, L.L.; Yu, G.T.; Wu, L.; Mao, L.; Deng, W.W.; Liu, J.F.; Kulkarni, A.B.; Zhang, W.F.; Zhang, L.; Sun, Z.J. STAT3 Induces Immunosuppression by Upregulating PD-1/PD-L1 in HNSCC. J. Dent. Res. 2017, 96, 1027-1034. [CrossRef]

47. Thorn, M.; Guha, P.; Cunetta, M.; Espat, N.J.; Miller, G.; Junghans, R.P.; Katz, S.C. Tumor-associated GM-CSF overexpression induces immunoinhibitory molecules via STAT3 in myeloid-suppressor cells infiltrating liver metastases. Cancer Gene Ther. 2016, 23, 188-198. [CrossRef]

48. Zhang, N.; Zeng, Y.; Du, W.; Zhu, J.; Shen, D.; Liu, Z.; Huang, J.A. The EGFR pathway is involved in the regulation of PD-L1 expression via the IL-6/JAK/STAT3 signaling pathway in EGFR-mutated non-small cell lung cancer. Int. J. Oncol. 2016, 49, 1360-1368. [CrossRef]

49. Nakayama, Y.; Mimura, K.; Tamaki, T.; Shiraishi, K.; Kua, L.F.; Koh, V.; Ohmori, M.; Kimura, A.; Inoue, S.; Okayama, H. Phospho-STAT1 expression as a potential biomarker for anti-PD-1/anti-PD-L1 immunotherapy for breast cancer. Int. J. Oncol. 2019, 54, 2030-2038. [CrossRef] 
50. Xue, W.; Li, W.; Zhang, T.; Li, Z.; Wang, Y.; Qiu, Y.; Wang, Y.; Chen, C.; Fu, D.; Zhang, M. Anti-PD1 up-regulates PD-L1 expression and inhibits T-cell lymphoma progression: Possible involvement of an IFN-gamma-associated JAK-STAT pathway. Oncotargets Ther. 2019, 12, 2079-2088. [CrossRef]

51. Verhoeven, Y.; Tilborghs, S.; Jacobs, J.; De Waele, J.; Quatannens, D.; Deben, C.; Prenen, H.; Pauwels, P.; Trinh, X.B.; Wouters, A.; et al. The potential and controversy of targeting STAT family members in cancer. Semin. Cancer Biol. 2020, 60, 41-56. [CrossRef]

52. Schildhaus, H.U. Predictive value of PD-L1 diagnostics. Der Pathol. 2018, 39, 498-519.

53. Kulangara, K.; Guerrero, L.; Posch, A.; Boyer, S.; Hanks, D.A.; Carnahan, J.; Wang, J.; Lunceford, J.; Savage, M.; Marton, M.J.; et al. Investigation of PD-L1 expression and response to pembrolizumab (pembro) in gastric cancer (GC) and cervical cancer (CC) using combined positive score (CPS) and tumor proportion score (TPS). J. Clin. Oncol. 2018, 36 (Suppl. 15), 4065. [CrossRef]

54. Karim, R.; Jordanova, E.S.; Piersma, S.J.; Kenter, G.G.; Chen, L.; Boer, J.M.; Melief, C.J.; van der Burg, S.H. Tumor-expressed B7-H1 and B7-DC in relation to PD-1+ T-cell infiltration and survival of patients with cervical carcinoma. Clin. Cancer Res. Off. J. Am. Assoc. Cancer Res. 2009, 15, 6341-6347. [CrossRef] [PubMed]

55. Heeren, A.M.; Rotman, J.; Stam, A.G.M.; Pocorni, N.; Gassama, A.A.; Samuels, S.; Bleeker, M.C.G.; Mom, C.H.; Zijlmans, H.; Kenter, G.G.; et al. Efficacy of PD-1 blockade in cervical cancer is related to a CD8(+)FoxP3(+)CD25(+) T-cell subset with operational effector functions despite high immune checkpoint levels. J. Immunother. Cancer 2019, 7, 43. [PubMed]

56. Noguchi, T.; Ward, J.P.; Gubin, M.M.; Arthur, C.D.; Lee, S.H.; Hundal, J.; Selby, M.J.; Graziano, R.F.; Mardis, E.R.; Korman, A.J.; et al. Temporally Distinct PD-L1 Expression by Tumor and Host Cells Contributes to Immune Escape. Cancer Immunol. Res. 2017, 5, 106-117. [CrossRef] [PubMed]

57. Dewulf, J.; Adhikari, K.; Vangestel, C.; Wyngaert, T.V.D.; Elvas, F. Development of Antibody Immuno-PET/SPECT Radiopharmaceuticals for Imaging of Oncological Disorders-An Update. Cancers 2020, 12, 1868. [CrossRef]

58. Li, D.; Cheng, S.; Zou, S.; Zhu, D.; Zhu, T.; Wang, P.; Zhu, X. Immuno-PET Imaging of (89)Zr Labeled Anti-PD-L1 Domain Antibody. Mol. Pharm. 2018, 15, 1674-1681. [CrossRef] [PubMed]

59. Li, M.; Ehlerding, E.B.; Jiang, D.; Barnhart, T.E.; Chen, W.; Cao, T.; Engle, J.W.; Cai, W. In vivo characterization of PD-L1 expression in breast cancer by immuno-PET with (89)Zr-labeled avelumab. Am. J. Transl. Res. 2020, 12, 1862-1872.

60. Vento, J.; Mulgaonkar, A.; Woolford, L.; Nham, K.; Christie, A.; Bagrodia, A.; de Leon, A.D.; Hannan, R.; Bowman, I.; McKay, R.M.; et al. PD-L1 detection using (89)Zr-atezolizumab immuno-PET in renal cell carcinoma tumorgrafts from a patient with favorable nivolumab response. J. Immunother. Cancer 2019, 7, 144.

61. McGrail, D.J.; Federico, L.; Li, Y.; Dai, H.; Lu, Y.; Mills, G.B.; Yi, S.; Lin, S.Y.; Sahni, N. Multi-omics analysis reveals neoantigenindependent immune cell infiltration in copy-number driven cancers. Nat. Commun. 2018, 9, 1317. [CrossRef]

62. Le, D.T.; Uram, J.N.; Wang, H.; Bartlett, B.R.; Kemberling, H.; Eyring, A.D.; Skora, A.D.; Luber, B.S.; Azad, N.S.; Laheru, D.; et al. PD-1 Blockade in Tumors with Mismatch-Repair Deficiency. N. Engl. J. Med. 2015, 372, 2509-2520. [CrossRef]

63. Goodman, A.M.; Kato, S.; Chattopadhyay, R.; Okamura, R.; Saunders, I.M.; Montesion, M.; Frampton, G.M.; Miller, V.A.; Daniels, G.A.; Kurzrock, R. Phenotypic and Genomic Determinants of Immunotherapy Response Associated with Squamousness. Cancer Immunol. Res. 2019, 7, 866-873. [CrossRef] [PubMed]

64. Hellmann, M.D.; Nathanson, T.; Rizvi, H.; Creelan, B.C.; Sanchez-Vega, F.; Ahuja, A.; Ni, A.; Novik, J.B.; Mangarin, L.M.B.; Abu-Akeel, M.; et al. Genomic Features of Response to Combination Immunotherapy in Patients with Advanced Non-Small-Cell Lung Cancer. Cancer Cell 2018, 33, 843-852.e4. [CrossRef]

65. Johnson, D.B.; Frampton, G.M.; Rioth, M.J.; Yusko, E.; Xu, Y.; Guo, X.; Ennis, R.C.; Fabrizio, D.; Chalmers, Z.R.; Greenbowe, J.; et al. Targeted Next Generation Sequencing Identifies Markers of Response to PD-1 Blockade. Cancer Immunol. Res. 2016, 4, 959-967. [CrossRef] [PubMed]

66. Singal, G.; Miller, P.G.; Agarwala, V.; Li, G.; Kaushik, G.; Backenroth, D.; Gossai, A.; Frampton, G.M.; Torres, A.Z.; Lehnert, E.M.; et al. Association of Patient Characteristics and Tumor Genomics With Clinical Outcomes Among Patients With Non-Small Cell Lung Cancer Using a Clinicogenomic Database. JAMA 2019, 321, 1391-1399. [CrossRef] [PubMed]

67. Vilain, R.E.; Menzies, A.M.; Wilmott, J.S.; Kakavand, H.; Madore, J.; Guminski, A.; Liniker, E.; Kong, B.Y.; Cooper, A.J.; Howle, J.R.; et al. Dynamic Changes in PD-L1 Expression and Immune Infiltrates Early During Treatment Predict Response to PD-1 Blockade in Melanoma. Clin. Cancer Res. 2017, 23, 5024-5033. [CrossRef]

68. Chae, Y.K.; Pan, A.; Davis, A.A.; Raparia, K.; Mohindra, N.A.; Matsangou, M.; Giles, F.J. Biomarkers for PD-1/PD-L1 Blockade Therapy in Non-Small-cell Lung Cancer: Is PD-L1 Expression a Good Marker for Patient Selection? Clin. Lung Cancer 2016, 17, 350-361.

69. Gibney, G.T.; Weiner, L.M.; Atkins, M.B. Predictive biomarkers for checkpoint inhibitor-based immunotherapy. Lancet Oncol. 2016, 17, e542-e551. [CrossRef]

70. Hugo, W.; Zaretsky, J.M.; Sun, L.; Song, C.; Moreno, B.H.; Hu-Lieskovan, S.; Berent-Maoz, B.; Pang, J.; Chmielowski, B.; Cherry, G.; et al. Genomic and Transcriptomic Features of Response to Anti-PD-1 Therapy in Metastatic Melanoma. Cell 2016, 165, 35-44. [CrossRef]

71. Owada-Ozaki, Y.; Muto, S.; Takagi, H.; Inoue, T.; Watanabe, Y.; Fukuhara, M.; Yamaura, T.; Okabe, N.; Matsumura, Y.; Hasegawa, T.; et al. Prognostic Impact of Tumor Mutation Burden in Patients With Completely Resected Non-Small Cell Lung Cancer: Brief Report. J. Thorac. Oncol. 2018, 13, 1217-1221. [CrossRef] 
72. Yang, S.; Wu, Y.; Deng, Y.; Zhou, L.; Yang, P.; Zheng, Y.; Zhang, D.; Zhai, Z.; Li, N.; Hao, Q.; et al. Identification of a prognostic immune signature for cervical cancer to predict survival and response to immune checkpoint inhibitors. Oncoimmunology 2019, 8, e1659094.

73. de Vos van Steenwijk, P.J.; Ramwadhdoebe, T.H.; Goedemans, R.; Doorduijn, E.M.; van Ham, J.J.; Gorter, A.; van Hall, T.; Kuijjer, M.L.; van Poelgeest, M.I.; van der Burg, S.H.; et al. Tumor-infiltrating CD14-positive myeloid cells and CD8-positive T-cells prolong survival in patients with cervical carcinoma. Int. J. Cancer. J. Int. Du Cancer 2013, 133, 2884-2894. [CrossRef] [PubMed]

74. Ngoi, N.Y.L.; Heong, V.; Lee, X.W.; Huang, Y.Q.; Thian, Y.L.; Choo, B.A.; Lim, D.; Lim, Y.W.; Lim, S.E.; Ilancheran, A.; et al. Tumor molecular profiling of responders and non-responders following pembrolizumab monotherapy in chemotherapy resistant advanced cervical cancer. Gynecol. Oncol. Rep. 2018, 24, 1-5. [CrossRef] [PubMed]

75. Vergote, I.B.; Concin, N.; Mirza, M.R.; Malmberg, A.; Eaton, L.; Nicacio, L.; Lorusso, D.; Soumaoro, I.; Monk, B.J.; O’Malley, D.M. Phase I/II trial of tisotumab vedotin plus bevacizumab, pembrolizumab, or carboplatin in recurrent or metastatic cervical cancer (innovaTV 205/ENGOT-cx8). Ann. Oncol. 2019, 30, v433-v434. [CrossRef]

76. Youn, J.W.; Hur, S.Y.; Woo, J.W.; Kim, Y.M.; Lim, M.C.; Park, S.Y.; Seo, S.S.; No, J.H.; Kim, B.G.; Lee, J.K.; et al. Pembrolizumab plus GX-188E therapeutic DNA vaccine in patients with HPV-16-positive or HPV-18-positive advanced cervical cancer: Interim results of a single-arm, phase 2 trial. Lancet. Oncol. 2020, 21, 1653-1660. [CrossRef]

77. Jazaeri, A.A.; Edwards, R.P.; Wenham, R.M.; MATSUO, K.; Fleming, G.F.; O’Malley, D.M.; Slomovitz, B.M.; Monk, B.J.; Brown, R.J.; Suzuki, S.; et al. A phase 2, multicenter study to evaluate the efficacy and safety using autologous tumor infiltrating lymphocytes (LN-145) in patients with recurrent, metastatic, or persistent cervical carcinoma. J. Clin. Oncol. 2018, 36 (Suppl. 15), TPS5604. [CrossRef]

78. Duska, L.R.; Showalter, T.N.; Petroni, G.R.; Bullock, T. A randomized phase II study of chemoradiation and pembrolizumab for locally advanced cervical cancer. J. Clin. Oncol. 2017, 35 (Suppl. 15), TPS5601. [CrossRef]

79. Fujiwara, K.; Shapira-Frommer, R.; Alexandre, J.; Monk, B.; Fehm, T.; Colombo, N.; Caceres, M.V.; Hasegawa, K.; Dubot, C.; Li, J.J.; et al. KEYNOTE-826: A phase III randomized study of chemotherapy with or without pembrolizumab for first-line treatment of persistent, recurrent, or metastatic cervical cancer. Ann. Oncol. 2019, 30, ix89-ix90. [CrossRef]

80. Lorusso, D.; Colombo, N.; Coleman, R.L.; Randall, L.M.; Duska, L.R.; Xiang, Y.; Hasegawa, K.; Rodrigues, A.N.; Cibula, D.; Mirza, M.R.; et al. ENGOT-cx11/KEYNOTE-A18: A phase III, randomized, double-blind study of pembrolizumab with chemoradiotherapy in patients with high-risk locally advanced cervical cancer. J. Clin. Oncol. 2020, 38 (Suppl. 15), TPS6096. [CrossRef]

81. Luke, J.J.; Powderly, J.D.; Merchan, J.R.; Barve, M.A.; Hotson, A.N.; Mobasher, M.; Kwei, L.; Luciano, G.; Buggy, J.J.; Piccione, E.; et al. Immunobiology, preliminary safety, and efficacy of CPI-006, an anti-CD73 antibody with immune modulating activity, in a phase 1 trial in advanced cancers. J. Clin. Oncol. 2019, 37 (Suppl. 15), 2505.

82. Lheureux, S.; Butler, M.O.; Clarke, B.; Cristea, M.C.; Martin, L.P.; Tonkin, K.; Fleming, G.F.; Tinker, A.V.; Hirte, H.W.; Tsoref, D.; et al. Association of Ipilimumab With Safety and Antitumor Activity in Women With Metastatic or Recurrent Human Papillomavirus-Related Cervical Carcinoma. JAMA Oncol. 2018, 4, e173776.

83. Ott, P.A.; Hodi, F.S.; Kaufman, H.L.; Wigginton, J.M.; Wolchok, J.D. Combination immunotherapy: A road map. J. Immunother. Cancer 2017, 5, 16. [CrossRef] [PubMed]

84. Shergold, A.L.; Millar, R.; Nibbs, R.J.B. Understanding and overcoming the resistance of cancer to PD-1/PD-L1 blockade. Pharmacol. Res. 2019, 145, 104258. [CrossRef]

85. van Dam, P.A.; Verhoeven, Y.; Jacobs, J.; Wouters, A.; Tjalma, W.; Lardon, F.; Van den Wyngaert, T.; Dewulf, J.; Smits, E.; Colpaert, C.; et al. RANK-RANKL Signaling in Cancer of the Uterine Cervix: A Review. Int. J. Mol. Sci. 2019, 20, 2183. [CrossRef] [PubMed]

86. van Dam, P.A.; Verhoeven, Y.; Trinh, X.B.; Wouters, A.; Lardon, F.; Prenen, H.; Smits, E.; Baldewijns, M.; Lammens, M. RANK/RANKL signaling inhibition may improve the effectiveness of checkpoint blockade in cancer treatment. Crit. Rev. Oncol. Hematol. 2019, 133, 85-91. [CrossRef] [PubMed] 